\title{
O Conhecimento dos Estudantes da Faculdade de Medicina de Marília (Famema) sobre Responsabilidade Profissional e Segredo Médico
}

\author{
Medical Students' Knowledge Concerning Physician \\ Responsibility and Patient Confidentiality at the \\ Marília School of Medicine in São Paulo State, Brazil
}

Ana Cristina Mendonça ${ }^{I}$ Heloísa Cerqueira C. E. Villar ${ }^{I}$ Selma Rumiko Tsuji ${ }^{I}$

\author{
PALAVRAS-CHAVE \\ - Ética médica. \\ - Estudantes de medicina. \\ - Educação médica. \\ - Ensino de graduação em \\ medicina. \\ - Bioética.
}

\section{Recebido em: 07/07/2008}

Reencaminhado em: 25/09/2008

Aprovado em: 24/10/2008

Introdução: O CFM instituiu o Código de Ética Médica (CEM), cuja violação implica sanções, impondo aos profissionais a ele submetidos seu conhecimento e aplicação, por meio de conduta permeada pelos prima facie ducties. Conhecer o assunto torna-se condição básica para sua observação. Daí a importância deste ensino desde os primeiros anos do curso médico, fornecendo ao estudante capacidade de análise ética na prática profissional futura. Objetivos: Avaliar o grau de conhecimento sobre as disposições do CEM relativas a "responsabilidade profissional" e "segredo médico" entre estudantes de Medicina da Famema e verificar se há evolução desse conhecimento durante a graduação. Método: Estudo realizado em dez meses, com 479 estudantes do primeiro ao sexto ano, regularmente matriculados. Aplicado questionário anônimo, com duas partes: uma com dados sociodemográficos e outra composta por 11 cenários clínicos, envolvendo questões eticamente conflituosas. Resultados: 395 estudantes responderam o questionário (82,46\% da amostra inicial). Ao se comparar a média total de acertos entre as turmas nos cenários, encontrou-se o valor de $p=0,7148$, sem significância estatística. Conclusões: Não há diferença estatisticamente significativa no grau de conhecimento sobre ética entre as séries. Sugere-se a introdução efetiva do assunto na graduação do curso médico, com metodologia de ensino adequada.

Introduction: The Brazilian National Board of Medicine (CFM) established the Medical Code of Ethics, the infringement of which involves sanctions and requires that physicians be familiar with and comply with it, by means of conduct governed by prima facie duties. Familiarity with the code is essential for adhering to it. Hence the importance of teaching the subject in the early years of undergraduate medical training, furnishing students with the skills for ethical analysis in their future professional practice. Objectives: Evaluate the degree of knowledge on the provisions of the Medical Code of Ethics concerning "physician responsibility" and "patient confidentiality" among students at the Marilia School of Medicine in São Paulo State, Brazil, and verify possible trends and changes in this knowledge during their undergraduate training. Method: The study covered a ten-month period, with an initial sample of 479 medical students (first to sixth years) that were presented with an anonymous questionnaire in two parts: one with socio-demographic data and the other with 11 clinical scenarios involving ethically conflictive issues. Results: 395 students answered the questionnaire (82.46\% of the initial sample). Comparison of the overall average number of correct answers among the various undergraduate years showed a p-value of 0.7148 , without statistical significance. Conclusions: We found no statistically significant difference in the degree of knowledge on medical ethics, when comparing the various years over the course of undergraduate medical training. The results thus suggest the need to introduce the subject of medical ethics into undergraduate medical education, with an appropriate didactic methodology. 


\section{INTRODUÇÃO}

O princípio básico que norteia qualquer relação humana é o da liberdade. Isso porque a liberdade de um indivíduo não termina onde começa a do outro. Na verdade, as liberdades individuais convivem simultaneamente, interpenetram-se em função das relações sociais. Portanto, não é possível traçar um limite preciso entre elas. Para que as liberdades individuais sejam respeitadas, é necessário que cada indivíduo conheça seus direitos e deveres e que estes sejam normatizados e, teoricamente, garantidos. Assim, o exercício da medicina, por ser uma relação bilateral, entre médico e paciente, também deve ser norteado por postulados que discorram sobre os direitos e deveres de ambos os sujeitos desta relação, observando, dessa forma, as liberdades individuais.

As primeiras regras escritas relativas aos princípios inerentes à própria profissão médica, reunidas em um corpo de doutrina, são atribuídas a Hipócrates (460-355 a.C.), considerado o pai da medicina. A escola hipocrática fundou os alicerces da medicina racional e científica e deu um sentido de dignidade à profissão médica. Entre os 72 livros que compõem o Corpus Hipocraticus destacam-se os dedicados à ética médica ${ }^{1}$. A ética é "uma ordenação teórico-prática dos comportamentos em geral, na medida e enquanto se destinam à realização de um bem" ${ }^{2}$. Assim, se a ética atribui uma ordenação ao comportamento humano, ela deve ser observada na prática médica, por lhe proporcionar, remetendo à sua origem grega (ethos significa abrigo, moradia), um habitat adequado ao exercício médico. O próprio juramento hipocrático corrobora esta ideia. A ética reafirma o ser humano como fim maior da medicina.

Ética e moral não são sinônimas. Na verdade, a primeira engloba a segunda, por fazer uma reflexão disciplinada de suas instituições. Moral é um conjunto de preceitos sociais relativos ao comportamento humano. Ordena a conduta numa sociedade, pois considera cada ação correta ou errada, tendo como base hábitos e costumes sociais consolidados. Tais convenções, por serem amplamente compartilhadas, tornam-se um consenso comum estável. As regras morais não possuem o caráter da coercibilidade, tampouco da atributividade. Portanto, a observação da moral deve ser espontânea ${ }^{2}$. Já os ditames éticos estão normatizados em legislação específica, como o Código de Ética Médica (Resolução CFM no 1.246/88).

Ética e Bioética também não se confundem. A Bioética é uma "nova ciência ética que combina humildade, responsabilidade e uma competência interdisciplinar e intercultural, que potencializa o senso de humanidade" ${ }^{\prime 3}$. É, portanto, mais ampla que a ética, por abranger várias disciplinas. Seu estudo não será alvo deste trabalho
A norma ética, como toda norma, expressa um juízo de valor, ou seja, fornece um caráter de obrigatoriedade a um valor que deve ser preservado e respeitado. Implica, portanto, um dever ser ${ }^{2}$. É bilateral, pois são necessários pelo menos dois sujeitos para a sua existência. É imperativa, por ser um mandamento. É coercitiva, pois é possível utilizar a força para o seu emprego. E é atributiva, uma vez que os sujeitos do ato têm a garantia da realização e cumprimento do mesmo.

O primeiro Código de Ética Médica Brasileiro, elaborado pelo Conselho Federal de Medicina (CFM), entrou em vigor em $1965^{1}$. Com as mudanças ocorridas no exercício da profissão médica e os avanços tecnológicos e científicos associados às alterações na dinâmica social e econômica do País, tornou-se necessária a reformulação deste Código e a promulgação de normatividade mais atualizada. Assim, o CFM, no uso de suas atribuições, aprovou, mediante a Resolução no ${ }^{-1.246 / 88, ~ u m ~ n o v o ~}$ Código de Ética Médica (CEM) ${ }^{4}$, em que normas fundamentais específicas disciplinam integral e isoladamente o exercício da medicina; as relações entre médico e seu cliente; entre médicos, e entre médico e instituição de saúde ou Estado. Este Código, portanto, possui caráter de lei, e suas determinações possuem respaldo na Constituição Federal Brasileira de 1988, legislação base das demais normas existentes no País. Logo, sua violação implica uma sanção, nas esferas disciplinar, penal e/ou cível. Isto porque toda ação ou omissão resulta numa consequência para o sujeito agente. Cada indivíduo é responsável pelo que faz; logo, também pelas consequências previsíveis de seus atos.

Dessa forma, é imprescindível conhecer os princípios éticos que orientam e embasam todos os preceitos do CEM para que estes sejam observados na prática médica e para que as normas éticas, que regulamentam a conduta profissional do médico, não sejam violadas, mas, sim, obedecidas. Os prima facie ducties, princípios fundamentais da ética descritos na literatura de Bioética ${ }^{5,6}$, são: (1) não-maleficência: obrigação de não provocar dano intencionalmente, primum non nocere; (2) justiça: engloba equidade, merecimento e direito; (3) beneficência: contribuir para o bem-estar do indivíduo; e (4) autonomia: abrange os direitos de privacidade, liberdade e escolha individual.

Os princípios éticos devem, portanto, nortear o exercício da medicina. As noções de não-maleficência e beneficência são essenciais à prática profissional e devem permear a postura e as atitudes do médico, fundamentando sua noção de responsabilidade. Da mesma forma, o atendimento médico deve contemplar a autonomia e ser justo para com o paciente, respeitando suas necessidades e contribuindo para amenizar seu problema, de ordem física e/ou psicológica. Portanto, a relação médico-paciente, base da prática médica, depende, fundamentalmente, da observação de tais princípios. 
O Capítulo III do CEM traz determinações relativas à responsabilidade profissional, positivando tais princípios éticos e garantindo, teoricamente, sua observação, uma vez que a violação de qualquer artigo poderá resultar em consequência disciplinar, penal e/ou cível. Assim, cada médico precisa ter, segundo Maimônides ${ }^{7}$ o espírito lúcido no exercício da prática médica, pois "grande e sublime é a ciência que tem por objetivo conservar a saúde e a vida de todas as criaturas".

O sigilo médico é um direito de todo paciente, e sua observação é fundamental para a garantia do princípio da autonomia. É direito defendido pelo atual CEM, no Capítulo IX, e pela Constituição $\mathrm{Federal}^{8}$, no artigo $5^{\mathrm{o}}$ e pelos Códigos Penal $^{9}$ e Civil ${ }^{10}$. O próprio juramento hipocrático positivou a necessidade de seu cumprimento: "Tudo aquilo que tenha ou não relação com a prática da minha profissão, ver ou ouvir da vida dos homens que não deva ser divulgado, não divulgarei, respeitando tudo aquilo que deva ficar secreto"11.

Tais normas não são absolutas e devem ser analisadas e aplicadas a cada caso.

O respeito às disposições relativas a responsabilidade profissional e segredo médico e, consequentemente, à ética é de suma importância para o exercício da medicina. O conhecimento do assunto é, portanto, condição básica para a sua observação. Daí a importância de seu ensino desde os primeiros anos do curso médico, pois o conhecimento solidificado no decorrer da formação médica é essencial à prática profissional futura.

\section{JUSTIFICATIVA}

O conhecimento é algo vivo e dinâmico e não um corpo de doutrinas a ser simplesmente resguardado e transmitido. Ter e usar o conhecimento não significam a mesma coisa. Seu exercício é que permite seu real aprendizado. “Ninguém poderá jamais aperfeiçoar-se se não tiver o mundo como mestre. A experiência se adquire na prática"12.

Assim, o conhecimento teórico sobre ética associado à prática clínica permite o aprendizado, sua observação espontânea e sua não violação no exercício da medicina. Conhecer o que é certo leva ao agir correto.

A metodologia de estudo da Famema, norteada pelo PBL (problem-based learning), forneceria, então, um cenário adequado a esta associação. Este método tem como características desenvolver no estudante a habilidade de gerenciar seu próprio aprendizado, integrar conhecimentos e explorar novas áreas ${ }^{13}$. Os alunos já possuem contato com a prática clínica e, consequentemente, com os pacientes, desde os primeiros anos do curso.

A estrutura curricular do curso de Medicina da Famema (1999) inclui a disciplina de Ética e Bioética nas matérias de Medicina Legal e Deontologia em todos os anos de formação ${ }^{14}$. Porém, resta saber se os problemas clínicos, base de ensino do
PBL, abordam este assunto adequadamente e se o aprendizado está sendo efetivo, o que constitui o objetivo deste trabalho.

A relação médico-paciente é fundamental para a prática médica $^{15}$. É baseada na confiança que o paciente deposita no médico e na empatia deste para com seu cliente. Assim, a observação e a garantia do segredo médico são condição sine qua non para estabelecer uma relação satisfatória, pois o paciente poderá revelar ao médico informações relativas à sua privacidade tendo a certeza de que não serão divulgadas ${ }^{16,17}$. A garantia do sigilo se aplica não somente às informações reveladas espontaneamente pelo paciente, como também às que forem descobertas no decorrer do atendimento ou tratamento. Além disso, este tema abrange diversas situações conflitantes, que podem trazer dúvidas ao médico, entre revelar e não revelar o segredo que lhe foi confiado durante o exercício de sua profissão.

De janeiro de 1996 a janeiro de 2002, o Conselho Regional de Medicina de São Paulo registrou 12 mil denúncias referentes a infrações no exercício da medicina. As mais frequentes são relacionadas à responsabilidade profissional, principalmente as relativas ao artigo 29 do $\mathrm{CEM}^{18}$. De janeiro de 2000 a dezembro de 2006, esse Conselho registrou 5.081 denúncias relativas à negligência médica, e 1.577, à relação médico-paciente ${ }^{18}$. Daí a importância de o estudante e futuro médico conhecer este assunto, tendo por base a ética da responsabilidade, que leva em conta as consequências e efeitos colaterais de cada ação ${ }^{19}$, para que sua conduta seja sempre permeada pela diligência, cautela e ponderação.

Dado o mérito da responsabilidade profissional e do segredo médico, é possível inferir que ambos os assuntos podem servir como tópicos indicadores do grau de conhecimento dos alunos sobre ética médica na Faculdade de Medicina de Marília.

Vários autores têm defendido a necessidade e a importância do ensino da Ética na formação médica ${ }^{20,21,22}$. Registros na literatura indicam a diminuição da sensibilidade e do conhecimento ético e moral dos estudantes no decorrer do curso de Medicina ${ }^{23,24}$. O presente trabalho também considera fundamental o aprendizado da Ética durante a vida acadêmica e, portanto, objetivou avaliar a qualidade desta formação, pois a instituição de ensino é responsável por fornecer ao estudante a capacidade de análise para que, na sua prática profissional, ele possa tomar decisões éticas.

\section{OBJETIVOS}

- Avaliar o grau de conhecimento sobre as disposições éticas dispostas no Código de Ética Médica (Resolução CFM no $1.246-88$ ) relativas à "responsabilidade profissional" e ao "segredo médico" entre os estudantes de Medicina do primeiro ao sexto ano da Faculdade de Medicina de Marília (Famema); 
- Avaliar se há diferença, entre as séries, no grau de conhecimento sobre as disposições éticas e se há evolução desse conhecimento no decorrer do curso médico.

\section{MATERIAL E MÉTODO}

O presente estudo, do tipo transversal, descritivo e analítico, foi realizado na Faculdade de Medicina de Marília (Famema), localizada na cidade de Marília, interior do Estado de São Paulo, de outubro de 2006 a agosto de 2007.

A população selecionada foi composta por 479 acadêmicos do curso médico, sendo 80 estudantes do primeiro ano (43 homens e 37 mulheres), 80 do segundo ano (49 homens e 31 mulheres), 78 do terceiro ano (36 homens e 42 mulheres), 81 do quarto ano ( 35 homens e 46 mulheres), 80 do quinto ano (31 homens e 49 mulheres) e 79 estudantes do sexto ano ( 25 homens e 54 mulheres). Os critérios de elegibilidade e inclusão utilizados consistiram na matrícula regular dos alunos no curso de Medicina. Foram excluídos do estudo os estudantes que se recusaram a assinar o termo de consentimento para a realização da pesquisa, aqueles transferidos de outras instituições de ensino e os que faltaram à(s) atividade(s) curricular(es) no momento da aplicação do instrumento.

A intervenção consistiu na aplicação de um questionário anônimo (Anexo 1), constituído por duas partes. A primeira - com dados sociodemográficos (idade, sexo, ano da graduação, local onde completou o ensino médio e fundamental, curso pré-vestibular, curso universitário anterior, especialidade médica que pretende seguir, grau de escolaridade da mãe e do pai) - visava caracterizar a amostra em estudo.

A segunda, o instrumento de avaliação, foi composta por 11 casos-vinheta. Cada cenário clínico abordava questões consideradas conflituosas na prática médica, relativas ao segredo médico (acesso ao prontuário, diagnóstico de HIV, depoimento como testemunha, menor de idade, empresas seguradoras e publicações) e à responsabilidade profissional (imprudência e negligência, plantão médico, aborto e atribuições da profissão). Havia duas alternativas como resposta, sendo que uma delas estava de acordo com os ditames do Código de Ética Médica e a outra não. O estudante deveria assinalar a postura que considerava ética. Nenhum questionário foi descartado por rasura ou preenchimento incorreto. $\mathrm{O}$ instrumento foi aplicado em cada série separadamente, durante atividade(s) acadêmica(s) eleita(s) previamente e com a permissão dos docentes responsáveis pelas turmas. A coleta dos dados foi realizada em um período único, de outubro a dezembro de 2006, com posterior análise das informações. De acordo com a Resolução 196, de 10 de outubro de 1996, cada participante assinou um termo de consentimento livre e esclarecido (Anexo 2) e ficou com uma cópia do mesmo, depositando o original e o questionário respondido em uma urna lacrada, destinada à sua série.

Do primeiro ao quarto ano, os questionários foram aplicados pelos docentes durante um dia de sessão de tutoria, que consiste em discussões em pequenos grupos (08 alunos) coordenados por docentes (tutores), sendo a proposta de aprendizagem do PBL a metodologia de ensino adotada pela Famema. Os tutores foram capacitados previamente. Durante a aplicação, orientaram os estudantes quanto à forma de responder o questionário. Todos os alunos de uma mesma série responderam-no simultaneamente, em data fixada, o que ocorreu em um período de cinco dias. Do quinto ao sexto ano, séries que constituem o internato, o instrumento foi aplicado pela própria pesquisadora. Desta vez, os alunos foram procurados por ela nos locais da instituição de ensino onde realizavam suas atividades curriculares, durante um período de dez dias, para a aplicação do questionário, respondido sob sua supervisão, devido à impossibilidade de reunião de todos os alunos em um único evento. Todos os alunos, contidos em lista oficial fornecida pela secretaria da Famema, foram abordados. Os questionários e formulários de consentimento foram colocados em urnas separadas para cada série no momento da devolução pelo próprio aluno.

Os questionários foram numerados aleatoriamente por série. Os dados foram, então, tabulados separadamente por meio do programa Windows Excel e, depois, unificados. A planilha foi transferida para o programa SPSS, onde foi realizada a análise estatística, complementada pelo programa GraphPad Instat. Foram calculados os valores de média e desvio padrão para variáveis numéricas e foi utilizado o teste qui-quadrado para o cálculo das frequências das variáveis categóricas. Não foi possível utilizar o modelo de regressão logística devido à homogeneidade da amostra em questão. Foram consideradas significativamente estatísticas as diferenças com nível de significância menor que $0,05 .{ }^{25}$ Os resultados obtidos permitiram a elaboração de tabelas e gráficos e a discussão da pergunta clínica proposta pelo trabalho.

Este estudo foi aprovado pelo Comitê de Ética em Pesquisa envolvendo seres humanos da Faculdade de Medicina de Marília de acordo com o protocolo de estudo nㅜ 174/06.

\section{RESULTADOS}

O questionário foi respondido, durante atividade acadêmica, por 395 estudantes do curso médico, o que corresponde a $82,46 \%$ da amostra inicialmente selecionada para o estudo, sendo 74 alunos da primeira série (40 homens e 34 mulheres), 69 da segunda (44 homens e 25 mulheres), 77 da terceira (35 homens e 42 mulheres), 66 da quarta (28 homens e $38 \mathrm{mu}$ lheres), 56 da quinta (20 homens e 36 mulheres) e 53 alunos 
TABELA 1

Dados sociodemográficos da população estudada

\begin{tabular}{|c|c|c|c|c|c|c|c|c|c|c|c|c|}
\hline \multirow{2}{*}{ Características } & \multicolumn{12}{|c|}{ Ano da Graduação } \\
\hline & 1asérie & & 2a série & & $3^{a}$ série & & $4^{\text {a }}$ série & & 5a série & & $6^{a}$ série & \\
\hline \multicolumn{13}{|l|}{ Idade } \\
\hline Média (anos) & 20,35 & & 21,35 & & 22,39 & & 23,59 & & 24,11 & & 24,98 & \\
\hline desvio padrão & 1,88 & & 1,9 & & 1,59 & & 2,14 & & 1,22 & & 1,35 & \\
\hline \multicolumn{13}{|l|}{ Pré-vestibular } \\
\hline Média (meses) & 22,7 & & 21,7 & & 24,3 & & 24,4 & & 20 & & 19,7 & \\
\hline \multirow[t]{2}{*}{ desvio padrão } & 13,4 & & 16,5 & & 15,5 & & 16,7 & & 12 & & 1,35 & \\
\hline & $\mathrm{N}=74$ & $\%$ & $\mathrm{~N}=69$ & $\%$ & $\mathrm{~N}=77$ & $\%$ & $\mathrm{~N}=66$ & $\%$ & $\mathrm{~N}=56$ & $\%$ & $\mathrm{~N}=53$ & $\%$ \\
\hline \multicolumn{13}{|l|}{ Sexo } \\
\hline Masculino & 40 & 54,1 & 44 & 63,8 & 35 & 45,5 & 28 & 42,4 & 20 & 35,7 & 18 & 34 \\
\hline Feminino & 34 & 45,9 & 25 & 36,2 & 42 & 54,5 & 38 & 57,6 & 36 & 64,3 & 35 & 66 \\
\hline \multicolumn{13}{|l|}{ Ens. Fundamental } \\
\hline Escola pública & 10 & 13,5 & 12 & 17,4 & 15 & 19,5 & 16 & 24,2 & 10 & 17,9 & 12 & 22,6 \\
\hline Particular & 64 & 86,5 & 27 & 82,6 & 62 & 80,5 & 50 & 75,8 & 46 & 82,1 & 41 & 77,4 \\
\hline \multicolumn{13}{|l|}{ Ensino Médio } \\
\hline Escola pública & 3 & 4,1 & 4 & 5,8 & 8 & 10,4 & 8 & 12,1 & 4 & 7,1 & 5 & 9,4 \\
\hline Particular & 71 & 95,9 & 65 & 94,2 & 69 & 89,6 & 58 & 87,8 & 52 & 92,9 & 48 & 90,6 \\
\hline \multicolumn{13}{|l|}{ Universidade } \\
\hline Sim & 5 & 6,8 & 3 & 4,3 & 5 & 6,5 & 5 & 7,6 & 3 & 5,4 & 1 & 1,9 \\
\hline Não & 69 & 93,2 & 66 & 95,7 & 72 & 93,5 & 61 & 92,4 & 53 & 94,6 & 52 & 98,1 \\
\hline \multicolumn{13}{|l|}{ Especialidade } \\
\hline Não definido & 33 & 44,6 & 32 & 46,4 & 34 & 44,2 & 16 & 24,2 & 7 & 12,5 & 3 & 5,7 \\
\hline Clínica & 18 & 24,3 & 11 & 15,9 & 16 & 20,8 & 17 & 25,8 & 15 & 26,8 & 15 & 28,4 \\
\hline Cirúrgica & 10 & 13,5 & 12 & 17,4 & 13 & 16,9 & 17 & 25,8 & 10 & 17,9 & 13 & 24,5 \\
\hline $\mathrm{GO}$ & 2 & 2,7 & 4 & 5,8 & 5 & 6,5 & 1 & 1,5 & 2 & 3,6 & 3 & 5,7 \\
\hline Pediatria & 4 & 5,4 & 3 & 4,3 & 2 & 2,6 & 6 & 9,1 & 8 & 14,3 & 4 & 7,5 \\
\hline PQ & 2 & 2,7 & 3 & 4,3 & 4 & 5,2 & 1 & 1,5 & 5 & 8,9 & 0 & 0 \\
\hline Outros & 5 & 6,8 & 4 & 5,8 & 3 & 3,9 & 8 & 12,2 & 9 & 16 & 15 & 28,3 \\
\hline \multicolumn{13}{|l|}{ Escolaridade mãe } \\
\hline Fund. incompleto & 2 & 2,7 & 6 & 8,7 & 3 & 3,9 & 4 & 6,1 & 1 & 1,8 & 0 & 0 \\
\hline Fund. completo & 4 & 5,4 & 4 & 5,8 & 6 & 7,8 & 3 & 4,5 & 4 & 7,1 & 10 & 18,9 \\
\hline Médio completo & 22 & 29,7 & 16 & 23,2 & 21 & 27,3 & 15 & 22,7 & 12 & 21,4 & 11 & 20,8 \\
\hline Superior completo & 34 & 45,9 & 37 & 53,7 & 38 & 49,3 & 39 & 59,1 & 33 & 59 & 25 & 47,1 \\
\hline Especialização & 12 & 16,3 & 6 & 8,6 & 9 & 11,7 & 5 & 7,6 & 6 & 10,7 & 7 & 13,2 \\
\hline \multicolumn{13}{|l|}{ Escolaridade pai } \\
\hline Fund. incompleto & 1 & 1,4 & 3 & 4,3 & 0 & 0 & 6 & 9,1 & 2 & 3,6 & 0 & 0 \\
\hline Fund. completo & 1 & 1,4 & 4 & 5,8 & 2 & 2,6 & 3 & 4,5 & 2 & 3,6 & 2 & 3,8 \\
\hline Médio completo & 19 & 25,7 & 17 & 24,6 & 22 & 28,6 & 15 & 22,7 & 10 & 17,9 & 11 & 20,8 \\
\hline Superior completo & 37 & 49,8 & 34 & 49,4 & 42 & 54,5 & 35 & 53,1 & 32 & 57,1 & 29 & 45,3 \\
\hline Especialização & 16 & 21,7 & 11 & 15,9 & 11 & 14,3 & 7 & 10,6 & 10 & 17,8 & 11 & 20,7 \\
\hline
\end{tabular}

da sexta série (18 homens e 35 mulheres). A caracterização da população estudada encontra-se na Tabela 1. Por meio de uma análise descritiva, foi possível constatar que a amostra em questão é homogênea, com excelente grau de concordância entre as respostas obtidas, não apresentando diferenças significativamente estatísticas entre os dados coletados nesta primeira parte do questionário. A média de idade entre os alunos foi de 22,61 anos, havendo uma progressão média de 0,76 ano a cada série, o que é esperado. A média de tempo de curso pré-vestibular foi de 22,34 meses. Quanto ao gênero, 210 mulheres responderam o questionário, perfazendo $81,08 \%$ do sexo feminino inicialmente selecionado, e 185 homens participaram da pesquisa, totalizando $84,47 \%$ da amostra masculina. Completaram o ensino fundamental e o ensino médio $81,01 \%$ 
GRÁFICO 1

Percentual do total de acertos nos cenários clínicos.

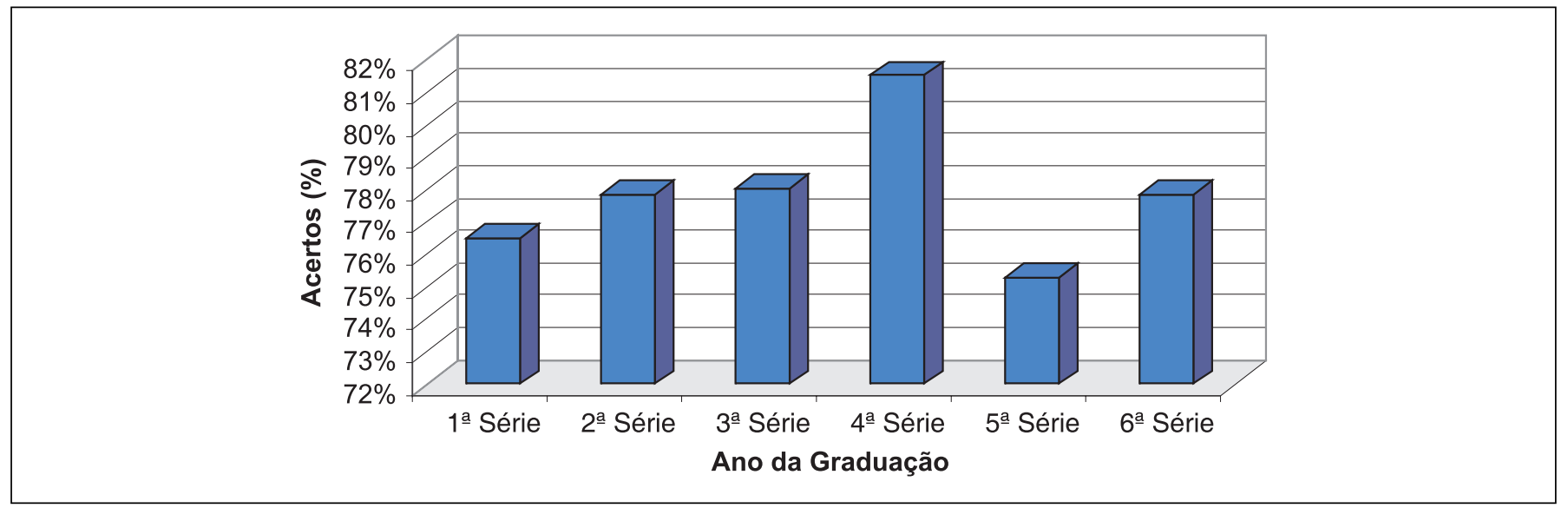

e 91,89\% dos estudantes, respectivamente, em escola particular, sendo que o valor de p encontrado na comparação das séries foi de 0,1848 e 0,2117. Da amostra em estudo, 94,43\% não possuem curso universitário anterior. A grande maioria dos alunos é oriunda de famílias cujos pais possuem grau superior completo de escolaridade, não havendo diferença estatística significativa quanto ao quesito escolaridade entre as séries. Possuem grau superior completo $63,54 \%$ das mães e $69,62 \%$ dos pais. Observou-se que o índice de indecisão quanto à especialidade médica a escolher diminui ao longo do curso, de $44,6 \%$ no primeiro ano para $5,7 \%$ no sexto, o que é plenamente justificável, tendo em vista a experiência vivenciada pelos alunos no decorrer dos anos. Clínica médica e cirurgia são as especialidades preferidas pelos estudantes em todas as séries. A homogeneidade da amostra se opõe à ideia inicial de que um fator de risco específico ou vários fatores confusionais, relativos à caracterização sociodemográfica, pudessem alterar a(s) variável(is) resposta(s).

Na comparação entre a média total de acertos dos estudantes de cada série nos cenários clínicos que envolviam questões éticas relacionadas ao segredo médico e à responsabilidade profissional, foi encontrado um valor de p igual a 0,7148 e o $\chi^{2}$ de 0,1336 . Isto mostra que não houve diferença estatisticamente significativa no grau de conhecimento sobre Ética nas turmas do curso médico da Famema. O Gráfico 1 demonstra que houve discreto aumento deste índice do primeiro ao quarto ano, com queda, em seguida, no quinto ano e tímida recuperação no sexto ano, porém sem significância estatística. $O$ Gráfico 2 mostra que o percentual de acertos em cada cenário clínico apresentado foi muito semelhante entre as turmas.

GRÁFICO 2.

Percentual de acertos por ano de graduação nos casos clínicos.

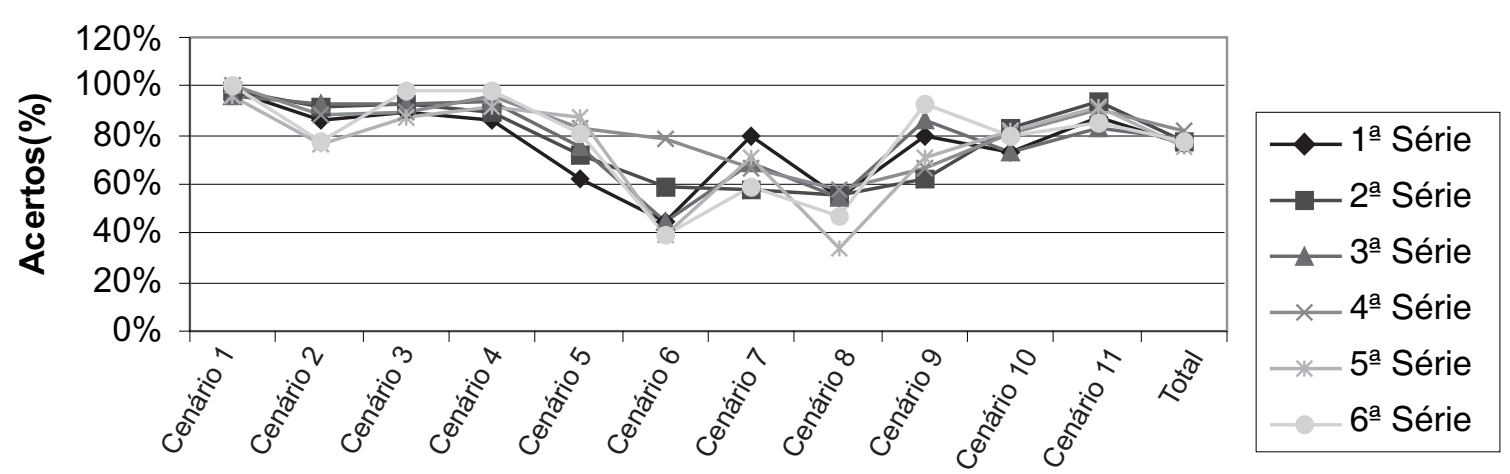

Casos clínicos 
Em análise mais detalhada, confrontando-se o percentual total de acertos entre as séries, turma a turma (Tabela 2), constatou-se que o valor de $\mathrm{p}$ foi superior a 0,05 na maioria das comparações. Foi inferior a 0,05, demonstrando significância, em apenas duas situações, na comparação entre o primeiro e quarto ano $(p=0,0192)$ e entre o quarto e quinto ano $(p=0,0068)$.

TABELA 2

Comparação da média de acertos nos cenários entre os anos da graduação (valores de p)

\begin{tabular}{ccccccc}
\hline Série & $\mathbf{1}^{\mathbf{a}}$ & $\mathbf{2}^{\underline{\mathbf{a}}}$ & $\mathbf{3}^{\mathbf{a}}$ & $\mathbf{4}^{\mathbf{a}}$ & $\mathbf{5}^{\mathbf{a}}$ & $\mathbf{6}^{\mathbf{a}}$ \\
\hline $1^{\underline{\mathbf{a}}}$ & $\mathbf{X}$ & 0,5701 & 0,5008 & 0,0192 & 0,6394 & 0,6016 \\
$2^{2^{\underline{a}}}$ & 0,5701 & $X$ & 0,9809 & 0,09 & 0,2962 & 0,9974 \\
$3^{\underline{\mathbf{a}}}$ & 0,5008 & 0,9809 & $\mathbf{X}$ & 0,0974 & 0,2486 & 0,992 \\
$4^{\underline{\mathbf{a}}}$ & 0,0192 & 0,09 & 0,0974 & $X$ & 0,0068 & 0,1147 \\
$5^{\underline{\mathbf{a}}}$ & 0,6394 & 0,2962 & 0,2486 & 0,0068 & $X$ & 0,3306 \\
$6^{\mathbf{a}}$ & 0,6016 & 0,9974 & 0,992 & 0,1147 & 0,3306 & $X$ \\
\hline
\end{tabular}

Comparando-se o índice de acertos das séries em cada cenário clínico, foi obtido valor de $p$ também superior a 0,05 , sem significância. Esta análise separada possibilitou observar que três casos clínicos que envolviam segredo médico (diagnóstico de HIV, intimação do Poder Judiciário e acesso ao prontuário) suscitaram dúvidas, o que justificaria o percentual de não acertos superior a 50\% e a maior discrepância no índice de acertos. A Tabela 3 demonstra que algumas turmas obtiveram índice de não acertos superior ao de acertos (4 séries no cenário 6 e 2 no cenário 8). O quinto e sexto anos apresentaram desempenho inferior ao das demais salas.

TABELA 3

Percentual de acertos nos cenários 6, 7 e 8

\begin{tabular}{cccc}
\hline \multirow{2}{*}{ Ano da graduação } & Cenário 6 & Cenário 7 & Cenário 8 \\
\cline { 2 - 4 } & $\mathbf{( \% )}$ & $\mathbf{( \% )}$ & $\mathbf{( \% )}$ \\
\hline $1^{\mathfrak{o}}$ & 44,59 & 79,72 & 54,05 \\
$2^{\mathrm{o}}$ & 59,42 & 57,97 & 55,07 \\
$3^{\mathrm{o}}$ & 44,15 & 68,83 & 54,54 \\
$4^{\mathrm{o}}$ & 78,78 & 66,66 & 57,57 \\
$5^{\mathrm{o}}$ & 39,28 & 71,42 & 33,92 \\
$6^{\circ}$ & 39,62 & 58,49 & 47,16 \\
\hline
\end{tabular}

\section{DISCUSSÃO}

A análise dos dados coletados nesta pesquisa demonstra que se trata de uma amostra homogênea, com elevado grau de concordância quanto aos aspectos sociodemográficos avaliados. Com isto, torna-se possível traçar um perfil do estudante de Medicina da Famema. Esta similaridade entre as turmas nos quesitos investigados não possibilitou a realização do modelo de regressão logística inicialmente proposto com o intuito de avaliar se os dados de caracterização da amostra teriam alguma influência nas respostas da segunda parte do questionário (cenários clínicos).

A realização do teste qui-quadrado para a análise da distribuição de frequência do total de acertos na comparação das seis séries nos cenários clínicos encontrou um valor de $\mathrm{p}$ igual a 0,7148 , sem significância estatística. Isto demonstra não haver diferença quanto ao grau de conhecimento dos estudantes sobre responsabilidade profissional e segredo médico e, consequentemente, dado o mérito destes temas, sobre ética médica. Com isso, também foi possível constatar que não houve evolução do conhecimento ético no decorrer da graduação.

Apesar de os estudantes apresentarem índice de acertos superiores aos de não acertos nas questões eticamente conflituosas, é provável que este conhecimento esteja ligado a valores prévios obtidos e solidificados pela formação intelectual e familiar de cada aluno e não tenha relação evidente com a formação médica oferecida pela instituição de ensino.

A quarta série demonstrou superioridade no nível de conhecimento em relação ao primeiro e quinto ano (valor de $\mathrm{p}$ inferior a 0,05$)$, como pode ser conferido na Tabela 2, fato que não conseguimos justificar, uma vez que as turmas apresentam estrutura e características similares. Nas demais comparações não foi encontrada significância estatística. Há discreta diferença no programa curricular do quinto e sexto anos em relação aos outros, ao abranger as atividades de Habilidades Profissionais e Interação Comunitária, que foram reformuladas em 2003, formando a Unidade de Práticas Profissionais, instituída a partir da quarta série, sendo estendida aos demais anos. É improvável que somente este fato justifique o desempenho citado, uma vez que a superioridade foi demonstrada sobre o quinto ano, com estrutura curricular diferente, e sobre o primeiro ano, com a mesma formação, não havendo diferença quanto às demais séries. O que poderia justificar o desempenho apresentado pelo quarto ano talvez seja a oportunidade de abordar o tema nas discussões em tutoria.

Para Pierre Weil, existem duas formas de ética, que se complementam: a ética moralista e a ética espontânea ${ }^{26}$. A primeira é algo adquirido, ou seja, informações exógenas que são internalizadas. Já a segunda surge de dentro do indivíduo, como algo natural. É possível inferir, portanto, que o conhecimento ético demonstrado pelos estudantes parece ser a ética espontânea de Weil, mais ligada à formação e ao contexto social onde eles estão inseridos do que às informações transmitidas durante o processo de aprendizagem no curso médico. Esta ideia poderia ser corroborada pelo fato de que 
as questões mais complexas, ou seja, que demandavam maior conhecimento do Código de Ética Médica, relativas ao sigilo, foram as que obtiveram maior discrepância no índice de acertos entre as turmas e maior índice de não acertos.

É provável que os alunos desconheçam as disposições éticas descritas no CEM, apesar da sua futura submissão a elas.

Em trabalho realizado na Famema em 2002 com o objetivo de avaliar o ensino da ética e a aquisição de conhecimento nesta área após a mudança de metodologia de ensino, mostrou-se que não houve diferença entre a turma do modelo tradicional e as demais, do PBL, e concluiu-se ser "necessário uma revitalização do ensino da Ética Médica" na instituição ${ }^{27}$. O presente trabalho, realizado no mesmo local, mostrou que as séries apresentam conhecimento similar sobre ética, não havendo evolução desse saber.

Vários autores constataram queda ou estacionamento na competência de julgamento moral e ético entre os acadêmicos no decorrer do curso de Medicina ${ }^{23,24,28}$. Estes registros estão em concordância com resultado obtido nesta pesquisa.

O conteúdo curricular da instituição, portanto, parece não ser decisivo no processo de ensino-aprendizagem nesta área, apesar de as disciplinas Ética e Bioética integrarem a grade curricular do curso.

Isto implica a necessidade de introdução precoce e efetiva do assunto na graduação, por intermédio de uma metodologia que associe conteúdo e prática, possibilitando ao aluno reconhecer situações eticamente conflituosas e utilizar os fundamentos éticos de forma a tomar, em sua prática profissional, decisões com autonomia e respeito ao indivíduo.

\section{CONCLUSÕES}

O estudo mostrou que não há diferença nem evolução, durante a graduação, no grau de conhecimento sobre as disposições do CEM relativas a "responsabilidade profissional" e "segredo médico" e, consequentemente, sobre ética médica entre os estudantes de Medicina da Famema. Apesar de o confronto turma a turma constatar superioridade quanto ao conhecimento do quarto ano em relação ao primeiro e quinto anos, na comparação da média total de acertos nos cenários clínicos não foi encontrada diferença significativamente estatística, indicando ausência de repercussão deste fato no quadro geral.

Piaget e Kohlberg afirmaram que "é necessário haver um conflito cognitivo", isto é, situações eticamente conflituosas que superem o "próprio estágio de desenvolvimento moral" do indivíduo ${ }^{29}$, um estímulo que perturbe o equilíbrio intelectual do estudante e o leve à percepção da limitação de seu raciocínio. Com isso, ele buscará meios para a resolução do conflito inicial, que funcionaria como a antítese hegeliana, es- timulando-o a elaborar uma nova síntese. Para tanto, o aluno e futuro médico precisa reconhecer as situações eticamente conflituosas para aplicar o seu conhecimento. Saber para observar na prática profissional.

Sugere-se, com isso, a introdução efetiva da ética médica no currículo do curso de Medicina da Famema, de forma a estimular a discussão do assunto nos diferentes cenários de aprendizagem. O PBL, por direcionar o processo de ensino-aprendizagem para o desenvolvimento da capacidade do estudante de construir ativamente seu conhecimento, forneceria ambiente adequado para associar conteúdo e experiência, possibilitando a aquisição do conhecimento num contexto prático.

\section{AGRADECIMENTOS}

Este trabalho foi desenvolvido com o auxílio financeiro do Conselho Regional de Medicina do Estado de São Paulo, fornecido por meio do Projeto de Bolsa de Pesquisa em Ética Médica. Agradecemos o apoio e o incentivo do Cremesp ao fomentar, no campo acadêmico, a pesquisa e a busca do conhecimento nesta área, fundamental para a formação médica. Agradecemos, ainda, à Profa. Dra. Maria Cláudia Cabrini Grácio pelas orientações fundamentais na área estatística.

ANEXO: O instrumento utilizado está disponível para consulta em http://www.educacaomedica.org.br/anexos

\section{REFERÊNCIAS}

1. Porto CC. Semiologia Médica. 4 ed. Rio de Janeiro: Guanabara Koogan; 2001. p. 18.

2. Reale M. Lições Preliminares de Direito. 23 ed. São Paulo: Saraiva; 1996. p. 39.

3. Potter VR. Palestra apresentada no IV Congresso Mundial de Bioética. O mundo da saúde. 1998;22(6):370-374.

4. Código de Ética Médica: e textos sobre ética, direitos e deveres dos médicos e pacientes. São Paulo: Conselho Regional de Medicina do Estado de São Paulo; 2001.

5. Beauchamp TL, Childress JF. Principles of biomedical ethics. 4rd.ed. New York: Oxford University Press; 1994.

6. Castilho EA, Kalil J. Ética e pesquisa médica: princípios, diretrizes e regulamentações. Rev soc bras med trop. 2005;38(4): 344-347.

7. Andrade ART, Muñoz JJA. De psico y farmacoterapia. Colóquio "La enfermedad y el enfermo", Simpósio da Seção de Psicoterapia da APAL, XIX Congresso da APAL. Mar del Plata, Argentina, abril de 1997.

8. Constituição da República Federativa do Brasil: promulgada em 5 de outubro de 1988.18 ed. atual. e ampl. São Paulo: Saraiva; 1988. 
9. Delamanto C. Código Penal comentado. 5 ed. Rio de Janeiro: Renovar; 2000.

10. Novo Código Civil: Lei no. 10406/2002. Belo Horizonte: Del Rey; 2003.

11. Oliveira JAP. Pareceres e resoluções: Sigilo ou segredo médico: a Ética e o Direito. Bioética. 2001;9(2):141-148.

12. Shakespeare W. Os dois cavalheiros de Verona.Ato I, cena III, Antônio. Rio de Janeiro: Relume Dumará; 1993.

13. Tibério IFLC, Atta JA, Lichtenstein. O aprendizado baseado em problemas-PBL. Rev medicina. 2003; 82(1/4):78-80.

14. Faculdade de Medicina de Marília. Grade curricular para os cursos de Medicina e Enfermagem. Marília; 1999.

15. Nascimento Júnior PG, Guimarães TMM. A relação médico-paciente e seus aspectos psico-dinâmicos. Bioética. 2003;11(1):101-114.

16. Publicações Cremesp. Prontuário e segredo médico. Disponível em: www.cremesp.org.br.

17. Vieira TR. Segredo médico enfrenta imposições legais. Áquila. 2000; 4(7):90-99.

18. Publicações Cremesp. Considerações sobre responsabilidade médica. Disponível em: www.cremesp.org.br.

19. Weber T. Ética e filosofia política: Hegel e o formalismo kantiano. Porto Alegre: Ed.PUCRS, 1999. p. 104.

20. Fox E, Arnold RM, Brody B. Medical ethics education: past, present, and future. Acad med.1995;70(9):761-769.

21. Grisard N. Ética médica e bioética: a disciplina em falta na graduação médica Bioética. 2002; 10(1):97-114.

22. Silva JTN, Miranda D, Marcolino JAM, Muñoz DR. Medida da sensibilidade ética em estudantes de Medicina: um estudo na Faculdade de Ciências Médicas da Santa Casa de São Paulo. Rev Bras Educ Med. 2005; 29(2):103-109.

23. Hebert PC, Meslin EM, Dunn EV, Reid SR. Measuring the ethical sensitivity of medical students: a study at the University of Toronto. J Med Ethics. 1992;18:142-147.
24. Lind G. Moral regression in medical students and their learning environment. Rev Bras Educ Med. 2000;24(3):24-33.

25. Castro AA. Projeto de pesquisa. [online]. [Acesso em: ]. Disponível em:http:/ / www.metodologia.org.

26. Gilles PW. A nova ética. Rio de Janeiro: Record; 2002.

27. Figueira EJG, Cazzo E, Tuma P, Silva Filho CR, Conterno LO. Apreensão de tópicos em ética médica no ensinoaprendizagem de pequenos grupos, comparando a aprendizagem baseada em problemas com o modelo tradicional. Rev assoc med bras. 2004;50(2):133-141

28. Patenaude J, Niyonsenga T, Fafard D. Changes in students' moral development during medical school: a cohort study. CMAJ. 2003;168(7):840-844.

29. Taquete SR, Rego S, Schramm FR, Soares LL, Carvalho SV. Situações eticamente conflituosas vivenciadas por estudantes de medicina. Rev assoc med bras. 2005;51(1):23-28.

\section{CONTRIBUIÇÃO DOS AUTORES}

Ana Cristina Mendonça: idealização do projeto de pesquisa, aplicação do instrumento, análise dos resultados, elaboração da discussão e conclusão e redação do texto. Heloísa Cerqueira C. E. Villar: orientação da metodologia da pesquisa, análise dos resultados e revisão final do texto. Selma Rumiko Tsuji: orientação da metodologia da pesquisa e revisão final do texto.

\section{CONFLITO DE INTERESSES}

Declarou não haver

\section{ENDEREÇO PARA CORRESPONDÊNCIA}

Ana Cristina Mendonça

Av. Antenor de Paula Pereira, 182

Penápolis - São Paulo

CEP.: 16300-000 - SP

E-mail: anacris_mendonca@yahoo.com.br 